\title{
Squeeze film lubrication of coupled stress electrically conducting inertial fluids in wide parallel rectangular conjunctions subjected to a magnetic field
}

\author{
M. Daliri ${ }^{1}$, D. Jalali-Vahid ${ }^{1}$ and H. Rahnejat ${ }^{2}$ \\ ${ }^{1}$ Sahand University of Technology, Tabriz, Iran \\ ${ }^{2}$ Wolfson School of Mechanical and Manufacturing Engineering, \\ Loughborough University, UK
}

\begin{abstract}
:
The paper presents analytical solution of squeeze film characteristics in wide parallel rectangular conjunctions with incompressible electrically conducting couple stress fluids, subjected to a magnetic field. Analytical expressions are obtained by combined solution of modified Reynolds equation and Stokes micro-continuum for couple stress fluids with averaged inertia. Various cases of magneto-hydrodynamic (MHD), conducting and non-conducting fluid characteristics with and without convective inertial contributions are investigated.

It is shown that in general couple stress fluids enhance the load carrying capacity of the contact and inhibit the incidence of thin films which can result in direct contact of surfaces. Convective inertia also significantly improves the load carrying capacity. However, with impulsive loading the response time of couple stress fluids deteriorates relative to Newtonian lubricants on account of their increased viscosity. An important conclusion of the study is that MHD couple stress fluids are best suited to applications with high relatively steady load applications.
\end{abstract}

Keywords: Magneto-Hydrodynamics, squeeze film action, couple stress fluid, convective inertia, Hartman number

\section{Introduction}

Load carrying capacity and reduced frictional losses are two essential requirements for lubricated conjunctions. This is particularly true for many machines and mechanisms which are progressively subjected to increased loading and higher speeds. They include modern turbo-machinery, such as turbo-chargers, with some now operating at speeds in excess of 200,000 rpm. Other applications include matching gears, hydraulic actuators and viscous dampers subjected to combined squeeze and shear loading.

The load carrying capacity of the usual lubricants is affected by temperature as their viscosity is significantly reduced at high shear rates. Additionally, at high contact pressures, lubricant viscosity is increased markedly with the repercussion of increased viscous friction, thus reduced operating efficiency. Therefore, across a range of operations, machines and mechanisms are subject to sub-optimal performance either due to increased viscous friction or poor load carrying capacity or both. Additionally, unusual contact geometries between moving parts may exist because of packaging constraints, which can inhibit the desired entraining motion of the lubricant into the 
contact. Therefore, an emerging trend has been to use electrically conducting fluids as lubricants in some machines and mechanisms. The aim is to avoid the undesirable and unpredictable changes in viscosity of lubricant with temperature and/or pressure. Thus, use of electro-rheological (ERF) lubricants, magneto- rheological fluids (MRF) and nano-fluids have been receiving increasing attention. These fluids which may be grouped as couple stress fluids are progressively used in machines subjected to non periodic impulsive or chaotic dynamic loads such as vehicle or train suspension dampers which are primarily subject to squeeze film motion [1,2]. MR- Damper mechanisms have also been employed in shear mode for variety of rotor applications to guard against vibration, for example, in vehicle power train systems [3,4].

A number of empirical and theoretical studies have investigated the performance characteristics of magneto-hydrodynamic (MHD) thin film bearings with different contact geometries in the presence of applied external magnetic fields. Some representative experimental and numerical studies include the study of MHD squeeze film characteristics by Maki and Kuzma[5], Usha and Vimala [6], Lin et al. [7] and Lin [8]. Additionally, Agrawal [9], Anwar and Rodkiewich [10], and Gupta and Bhat [11] have studied the lubricant behaviour in MHD slider bearings.

With the development of some modern machine elements the use of a small quantity of additives to the lubricant has become of interest. These additive particles can be, for example, high molecular weight polymers or ferromagnetic particles. The rheological flow behaviour of a Newtonian lubricant, blended with various additives cannot be accurately described by the classical continuum theory. Therefore, many micro-continuum theories have been proposed [12-14]. One involves the use of the "couple stress" concept, which was originally developed to model non-Newtonian fluids such as synthetic fluids, polymer-thickened oils, liquid crystals, and even blood. In this method the sizes of blended particles are important.

By making use of this approach some analytical and numerical studies for squeeze film lubrication have been reported. Ramanaish and Sarkar [15] studied squeeze film lubrication in thrust bearings as well as finite parallel plates with different geometrical shapes (Ramanaish [16]). Lin [17,18] studied squeeze film lubrication of a long partial journal bearing, as well as a hemispherical bearing. The effect of fluid inertia was considered by Lin et al [19] in parallel wide rectangular plates. Das [20] studied lubrication of slider bearings with an MHD coupled stress fluid as the lubricant and in the presence of an external magnetic field. Recently, Naduvinamani and Rajashekar [21] investigated the effect of MHD coupled stress fluid on the squeeze film behaviour for the classical ball-on-plate geometry.

Hitherto, the characteristics of a squeeze film between two parallel wide rectangular plates with an MHD coupled stress fluid in the presence of an external magnetic field, including inertial effects has not been studied. The current study undertakes this approach, using the Stokes coupled stress fluid model and the principle of averaged inertia. The modified Reynolds equation, governing the squeeze film pressure is derived, based on Stokes micro-continuum and averaged inertia. The results of squeeze film characteristics such as the load carrying capacity and time history of film thickness are presented for various values of couple stress parameter, lubricant inertia and Hartman's number. 


\section{The analytical approach}

The geometry of problem is shown in figure 1. It is assumed that the squeeze velocity between the plates remains constant. Since the plates are considered to be wide, any side leakage flow from the conjunction in the $y$ direction is neglected. It is necessary to calculate the flow parameters such as the pressure distribution, load carrying capacity and film thickness in the solution of the problem. Momentum equations for a MHD coupled stress fluid are used in the presence of a uniform magnetic field, including the fluid inertia. Therefore, the governing equations are derived as follows (see the Nomenclature in Appendix A):

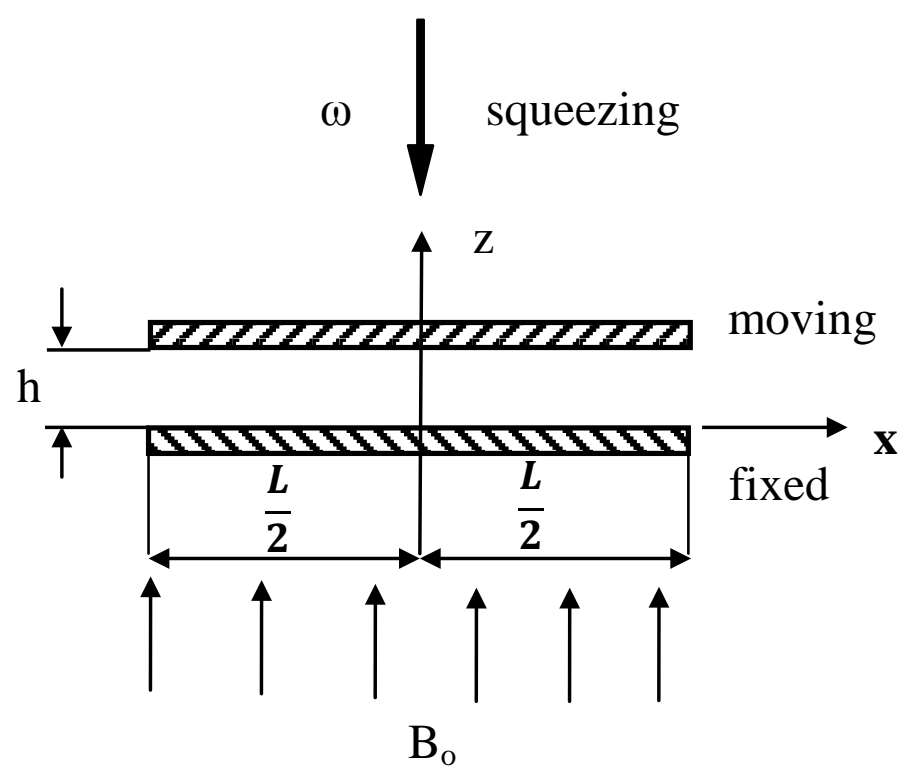

Fig1. Squeeze film geometry between two wide parallel plates.

$$
\begin{aligned}
& \rho\left(u \frac{\partial u}{\partial x}+w \frac{\partial u}{\partial z}\right)=-\frac{\partial p}{\partial x}+\mu \frac{\partial^{2} u}{\partial z^{2}}-\eta \frac{\partial^{4} u}{\partial z^{4}}-\sigma B_{o}{ }^{2} u \\
& \frac{\partial p}{\partial z}=0
\end{aligned}
$$

The continuity of flow condition with no side leakage yields:

$$
\frac{\partial u}{\partial x}+\frac{\partial w}{\partial z}=0
$$

where $u$ and $w$ are velocity components in the $x$ and $z$ directions respectively, $\eta$ is the material constant responsible for the coupled stress fluids, $\sigma$ is the electrical conductivity of the lubricant and $B_{o}$ represents the applied magnetic field. With noslip condition at the conjunctional surfaces, no-coupled stress condition [12] and also zero pressure at the conjunctional boundaries:

$$
u=0, \quad \frac{\partial^{2} u}{\partial z^{2}}=0, w=0 \text { at } z=0
$$




$$
\begin{aligned}
& u=0, \quad \frac{\partial^{2} u}{\partial z^{2}}=0, w=\frac{d h}{d t} \quad \text { at } z=h \\
& p=0, \quad \text { at } x= \pm \frac{L}{2}
\end{aligned}
$$

Since the lubricant film is thin, the inertial forces are assumed to remain constant in equation (1). Therefore, integrating over the film thickness and considering the mean value of inertial forces, equation (1) can be written as:

$\frac{\rho}{h} \int_{z=0}^{h}\left(u \frac{\partial u}{\partial x}+w \frac{\partial u}{\partial z}\right) d z+\frac{\partial p}{\partial x}=\mu \frac{\partial^{2} u}{\partial z^{2}}-\eta \frac{\partial^{4} u}{\partial z^{4}}-\sigma B_{o}{ }^{2} u$

By introducing the modified pressure gradient:

$g_{m p}=\frac{\rho}{h}\left(\frac{\partial}{\partial x} \int_{z=0}^{h} u^{2} d z\right)+\frac{\partial p}{\partial x}$

then, equation (7) becomes:

$\mu \frac{\partial^{2} u}{\partial z^{2}}-\eta \frac{\partial^{4} u}{\partial z^{4}}-\sigma B_{o}{ }^{2} u=g_{m p}$

Making use of non-dimensional parameters:

$\mathrm{l}=(\eta / \mu)^{1 / 2}, \quad \mathrm{a}=1 / l^{*}, l^{*}=l / h_{o}, z^{*}=\frac{z}{h_{o}}, u^{*}=\frac{\mu u}{h_{o}{ }^{2}\left(-g_{m p}\right)}, h^{*}=\frac{h}{h_{o}}, M=B_{o} h_{o} \sqrt{\frac{\sigma}{\mu}}$

the dimensionless form of equation (9) becomes:

$\frac{\partial^{4} u^{*}}{\partial z^{*}}-a^{2} \frac{\partial^{2} u^{*}}{\partial z^{* 2}}+M^{2} a^{2} u^{*}=a^{2}$

The non-dimensional boundary conditions are:

$$
\begin{aligned}
& u^{*}=0, \frac{\partial^{2} u^{*}}{\partial z^{* 2}}=0 \quad \text { at } z^{*}=0 \\
& u^{*}=0, \frac{\partial^{2} u^{*}}{\partial z^{* 2}}=0 \quad \text { at } z^{*}=h^{*}
\end{aligned}
$$

The boundary conditions (12) and (13) are used for the solution of equation (11). This yields the non-dimensional velocity distribution inside the lubricant film. Three different cases are considered according to the parameter, $n$ : 
$n=\frac{2 M}{a}=\frac{2 B_{o} h_{o}(\sigma / \mu)^{1 / 2}}{1 / l^{*}}=\frac{2 B_{o} h_{o}(\sigma / \mu)^{1 / 2}}{1 / \frac{l}{h_{o}}}$

which simplifies to: $n=\frac{2 M}{a}=2 \mathrm{~B}_{\mathrm{o}} l \sqrt{\sigma / \mu}$

It can be seen that for a constant viscosity condition, $n$ is a direct function of the magnetic field intensity, fluid electrical conductivity and the material constant. By increasing these quantities, an enhancement in the value of $n$ would be expected. This yields a higher load carrying capacity. Analytic solution for three cases: Case 1: $n<1$, Case 2: $n=1$ and Case 3: $n>1$ are outlined in Appendix B.

Load carrying capacity is obtained by integration of Pressure distribution $p^{*}$ (derived in Appendix B). Therefore, the dimensionless load carrying capacity per unit width (Note: $\frac{W}{b}=\int_{x=-\frac{L}{2}}^{\frac{L}{2}} p d x$ ), for Cases 1-3 becomes:

\section{(a)- Case 1:}

$W^{*}=\frac{W h_{o}^{3}}{\mu L^{3} b \omega}=\frac{-1}{12}\left(\frac{1}{f_{0}^{*}\left(h^{*}, M, a\right)}-\frac{2 \operatorname{Re} f_{1}^{*}\left(h^{*}, M, a\right)}{h^{*} f_{0}^{2} *\left(h^{*}, M, a\right)}\right)$

For $R e=0$, equation (35) converts to:

$W^{*}=\frac{-1}{12}\left(\frac{1}{f_{0}^{*}\left(h^{*}, M, a\right)}\right)$

which is the usual expression for the non-inertial fluid flow condition.

In the absence of a magnetic field (i.e. $M=0$ ), equation (14) represents the dimensionless load carrying capacity for a non-Newtonian coupled stress model fluid, which was studied by Lin[19].

The case represented by: $R e=0, M=0$ and $l^{*}=0 \quad(a \rightarrow \infty)$ is for a non-conducting Newtonian fluid in a non-inertial flow condition. Then, equation (15) for $h^{*}=1$ convert to:

$W^{*}=1$

Equation (16) is that obtained by Hamrock [22] for this case.

\section{(b)- Case 2:}

$$
W^{*}=\frac{-1}{12}\left(\frac{1}{g_{0} *\left(h^{*}, M, a\right)}-\frac{2 \operatorname{Re} g_{1}^{*}\left(h^{*}, M, a\right)}{h^{*} g_{0}^{2} *\left(h^{*}, M, a\right)}\right)
$$




\section{(c) - Case 3:}

$$
W^{*}=\frac{-1}{12}\left(\frac{1}{r_{0}^{*}\left(h^{*}, M, a\right)}-\frac{2 \operatorname{Re} r_{1}^{*}\left(h^{*}, M, a\right)}{h^{*} r_{0}{ }^{*}\left(h^{*}, M, a\right)}\right)
$$

The dimensionless response time is:

$$
t^{*}=\frac{W h_{o}^{2}}{\mu L^{3} b} t
$$

The time history of film thickness is obtained by making use of equations (14), (17) and (18) for case 1, case 2 and case 3, respectively as:

$$
\frac{d h^{*}}{d t^{*}}=\frac{12}{\left(\frac{1}{f_{0} *\left(h^{*}, M, a\right)}-\frac{2 \operatorname{Re} f_{1}^{*}\left(h^{*}, M, a\right)}{h^{*} f_{0}{ }^{2}\left(h^{*}, M, a\right)}\right)}
$$

$$
\frac{d h^{*}}{d t^{*}}=\frac{12}{\left(\frac{1}{g_{0} *\left(h^{*}, M, a\right)}-\frac{2 \operatorname{Re} g_{1}^{*}\left(h^{*}, M, a\right)}{h^{*} g_{0}{ }^{2}\left(h^{*}, M, a\right)}\right)}
$$

$$
\frac{d h^{*}}{d t^{*}}=\frac{12}{\left(\frac{1}{r_{0} *\left(h^{*}, M, a\right)}-\frac{2 \operatorname{Re} r_{1}^{*}\left(h^{*}, M, a\right)}{h^{*} r_{0}{ }^{*}\left(h^{*}, M, a\right)}\right)}
$$

The above equations are highly non-linear ordinary differential equations. Therefore, the solution method should shift from analytical to a numerical one. In order to achieve accurate results a higher-order Runge-Kutta method is used taking into account the following initial condition:

$$
h^{*}=1 \quad \text { at } \quad t^{*}=0
$$

\section{3-Results and discussion:}

A Magnetorheological lubricant in the conjunction of a pair of wide parallel rectangular plates subjected to a magnetic field is considered. Tables 1 and 2 in Appendix $C$ list the lubricant rheological and magnetic field parameters used in the current study. In tables 1 and 2, the parameter, $a$ represents the effect of coupled stresses, $M$ shows the effect of external magnetic field and the Reynolds' number, Re defines the effect of inertial loading on the squeeze film action. It should be noted that only in the case 1 : $\left(\frac{2 M}{a}\langle 1), l^{*}\right.$ and $M$ can diminish, which yields Newtonian and 
non-conducting fluids respectively. In cases 2 and 3: $M=0$ or $l^{*}=0(a \rightarrow \infty)$ would have no physical meaning and thus such cases cannot be interpreted.

Pressure distribution, load carrying capacity and film thickness are obtained for the 3 different cases. The effect of fluid inertia is considered, as well as the Stokes microcontinuum theory. The principle of averaged inertia is used for analyzing the squeeze film characteristics.

The generated lubricant pressure distribution for different values of $M, R e$ and $a$ are shown in figures 2-5. When the values of $M, R e$ and ${ }_{l}^{*}$ increase (i.e. a decreasing value of $a$ ), the maximum lubricant pressure is enhanced. This is because an increasing Hartman number, $M$ and coupled stress parameter ${ }^{*}$ increase the lubricant viscosity, thus the pressure distribution and hence the load carrying capacity.

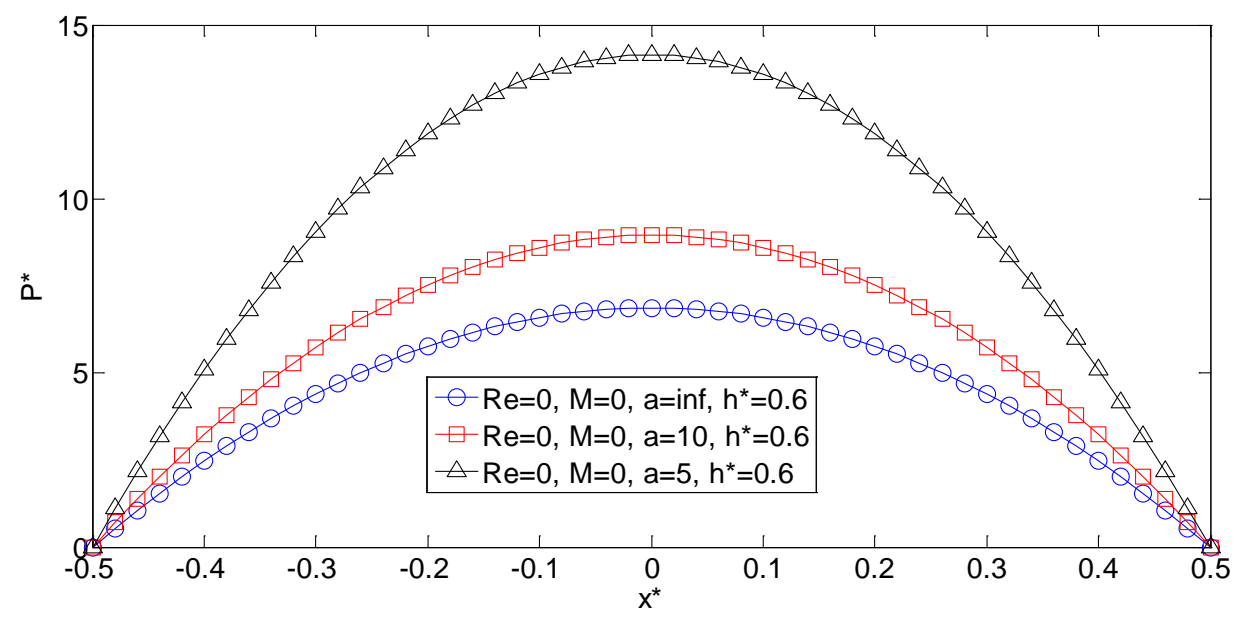

Fig.2: Dimensionless pressure distribution for the case $1,\left(\frac{2 M}{a}\langle 1)\right.$

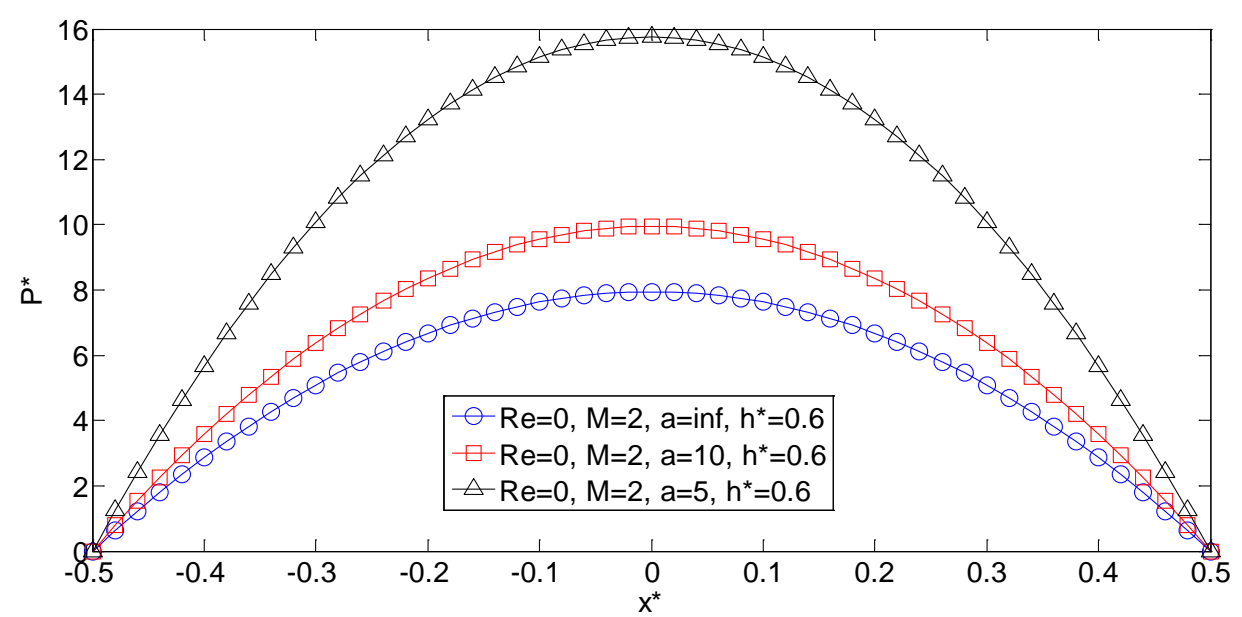

Fig.3: Dimensionless pressure distribution for the case $1,\left(\frac{2 M}{a}\langle 1)\right.$ 


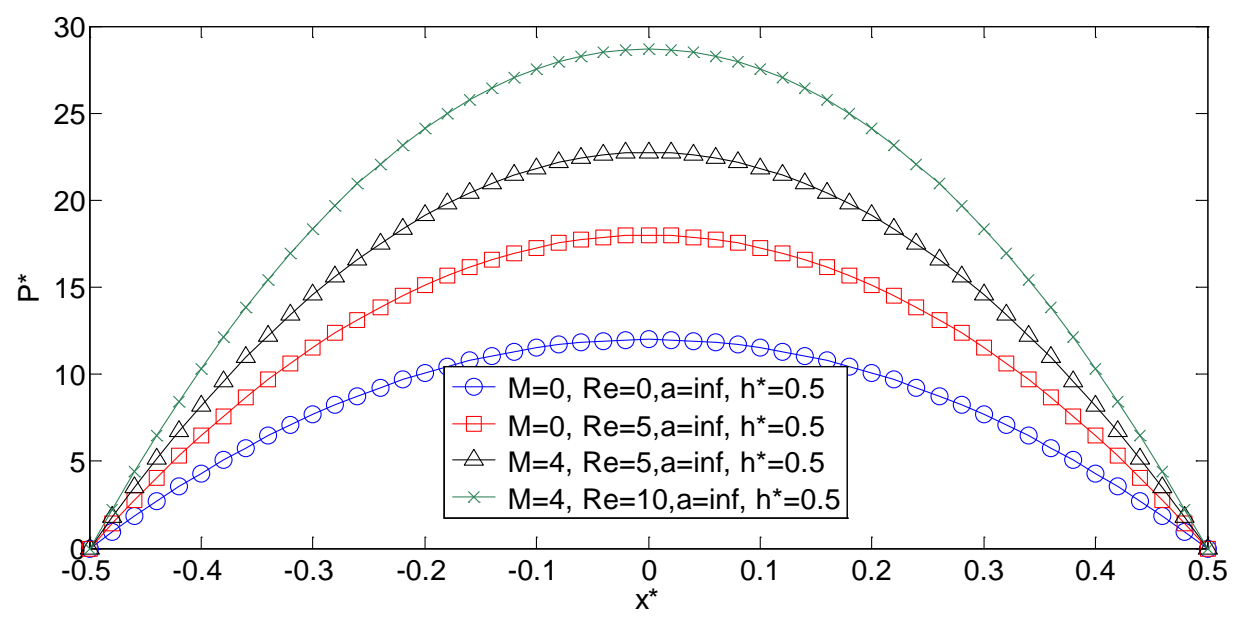

Fig.4: Dimensionless pressure distribution for the case $1,\left(\frac{2 M}{a}\langle 1)\right.$

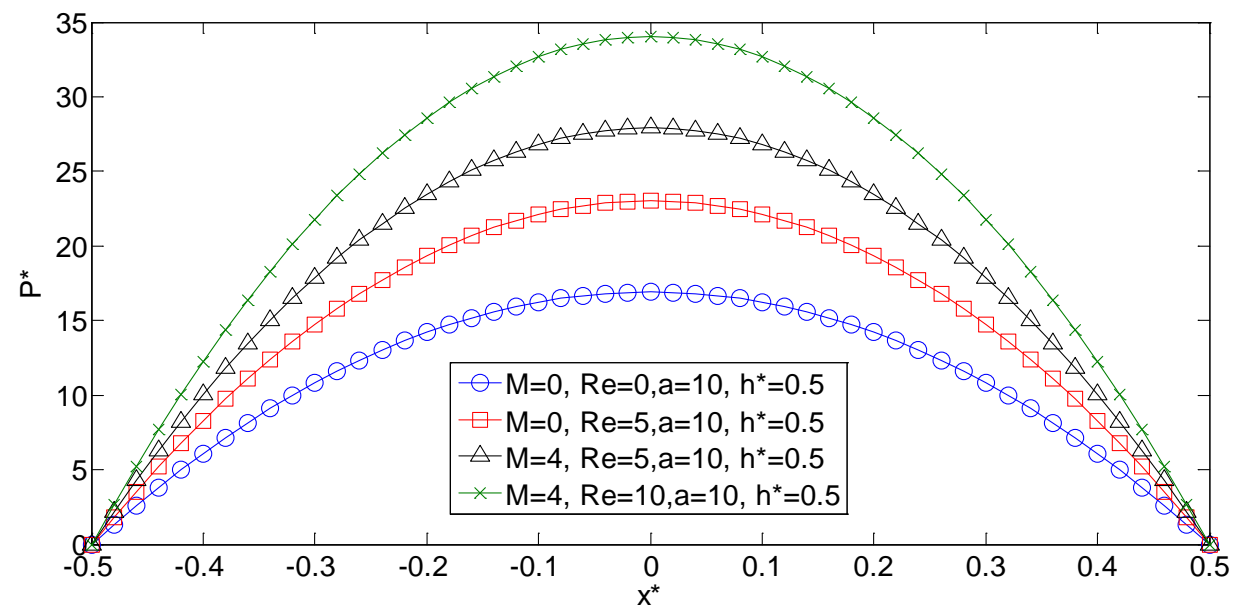

Fig.5. Dimensionless pressure distribution for the case $1,\left(\frac{2 M}{a}\langle 1)\right.$

Figures 6-8 show the variation of dimensionless load carrying capacity $W^{*}$ with the coupled stress parameter $l^{*}$ for different values of dimensionless film thickness $h^{*}$ for non-inertial non-conducting $(R e=0, M=0)$, non-inertial conducting and inertial conducting fluids respectively. Since the coupled stress effect yields a higher film pressure, then the load carrying capacity increases accordingly. In fact, as shown in Figures 6-8, the load carrying capacity is a function of $l^{*}$ as would rationally be expected (increasing $l^{*}$ improves the load carrying capacity). This finding indicates that the least load carrying capacity is attained in the case of a Newtonian fluid. Clearly, also reducing $h^{*}$ yields increased loading. This is evident in, for example equation (36), except for non-inertial flow condition, where there is no dependence on $h^{*}=1$. On the other hand, increasing $R e$ and $M$ will naturally increase $W^{*}$. 


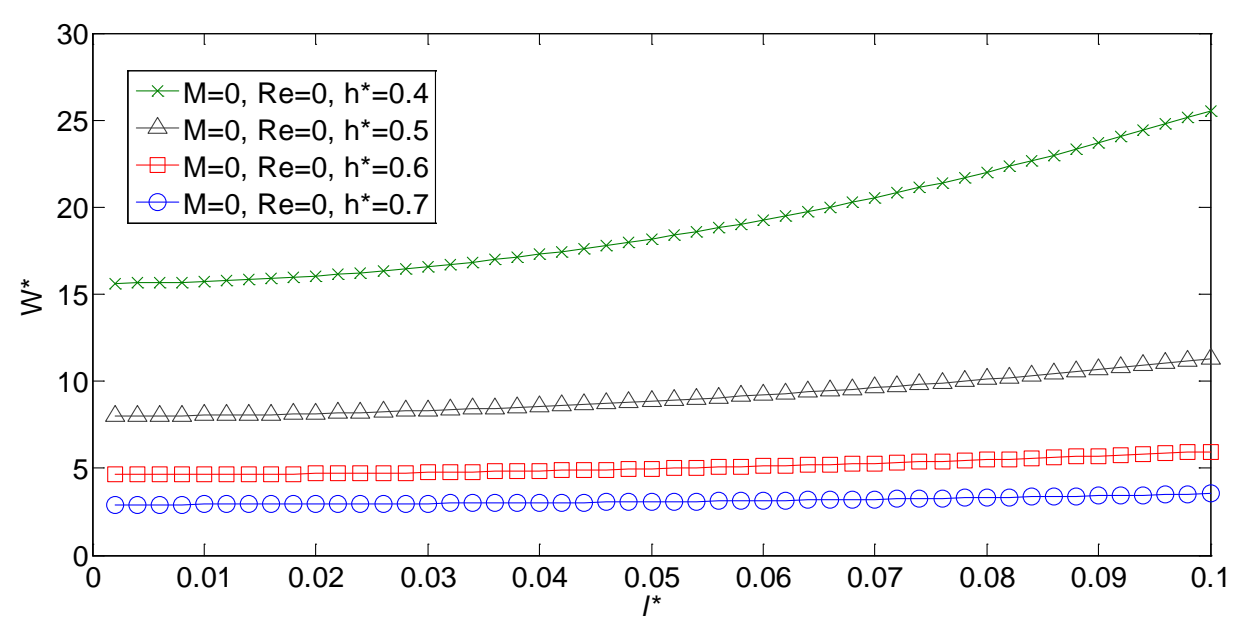

Fig.6: Variation of load capacity $\mathrm{W}^{*}$ with couple stress parameter $l^{*}$ for the case1: $\left(\frac{2 M}{a}\langle 1)\right.$

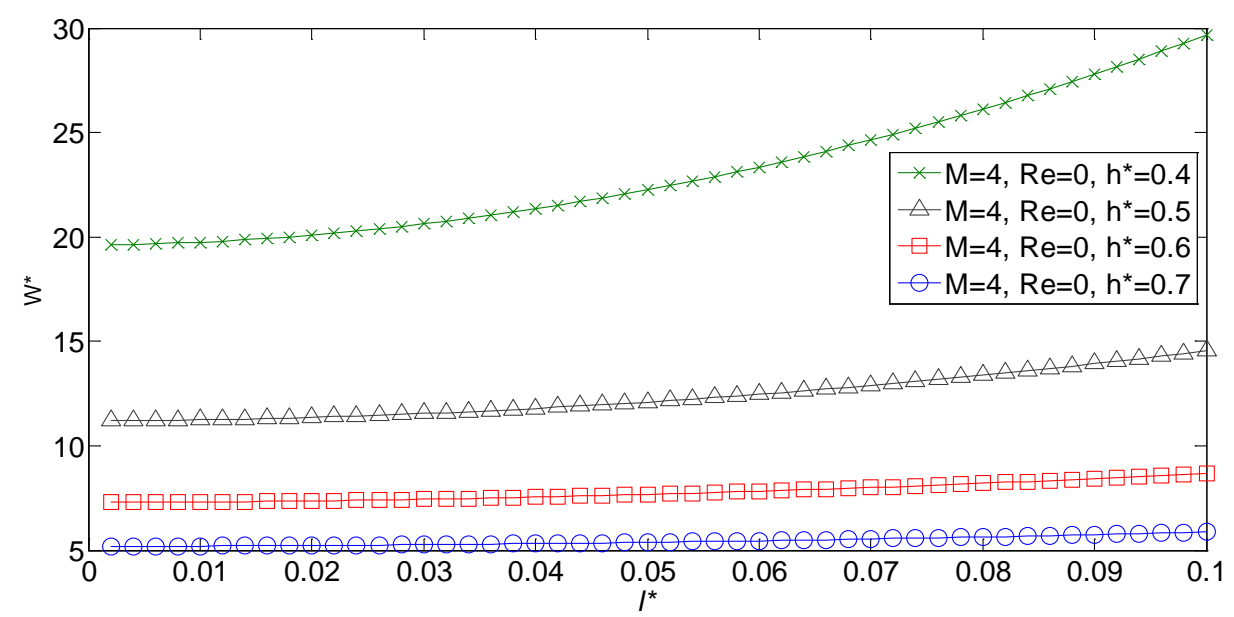

Fig.7: Variation of load capacity $\mathrm{W}^{*}$ with couple stress parameter $l^{*}$ for the case1: $\left(\frac{2 M}{a}\langle 1)\right.$

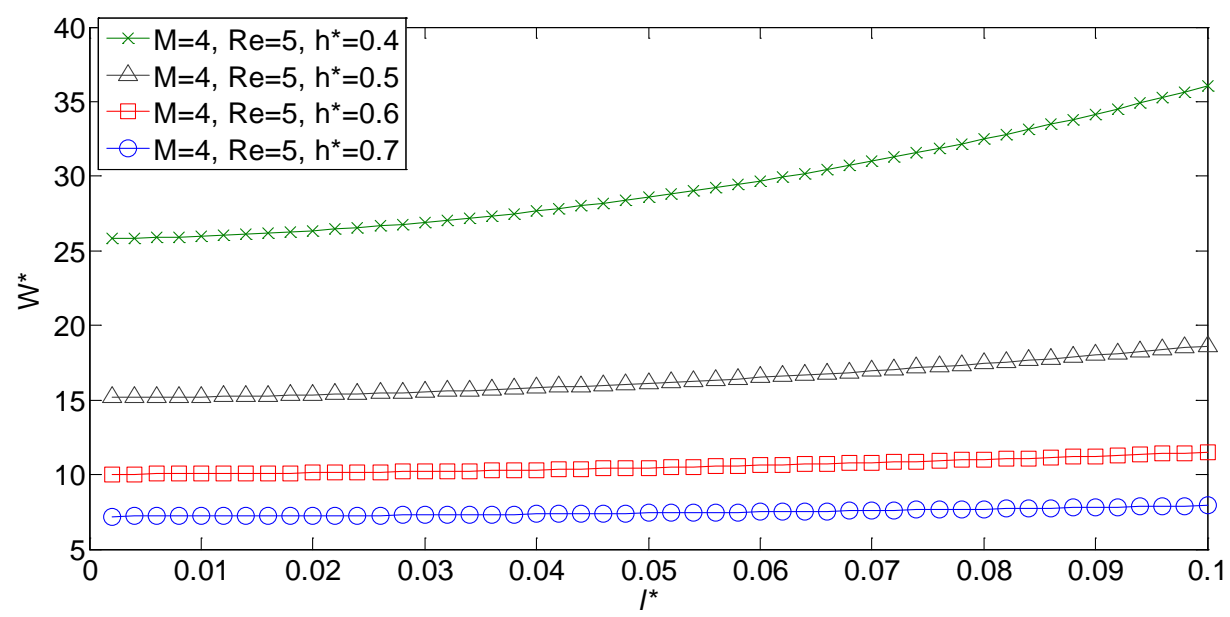

Fig.8: Variation of load capacity $\mathrm{W}^{*}$ with couple stress parameter $l^{*}$ 


$$
\text { for the case1: }\left(\frac{2 M}{a}\langle 1)\right.
$$

Aside from load carrying capacity as a performance measure for contacts, in order to guard against incidence of direct contact of solid surfaces, the response time to applied loads, particularly those leading to squeeze of lubricant film is an important measure of performance. Figures 9-10 show the variation of dimensionless film thickness $h^{*}$ with dimensionless response time $t^{*}$ for different values of the inverse coupled stress parameter $a$ under both non-inertial and non-conducting ( $R e=0$, $M=0)$ ) and non-inertial conducting $(R e=0, M=4)$ conditions. It is shown that for a non-Newtonian fluid the response time is longer than for a Newtonian one, although the ultimate load carrying capacity is conversely true (see figures 6-8). The physical implication of these results is that for certain impulsive loading conditions (depending on the maximum applied load) the Newtonian fluids may actually perform better.

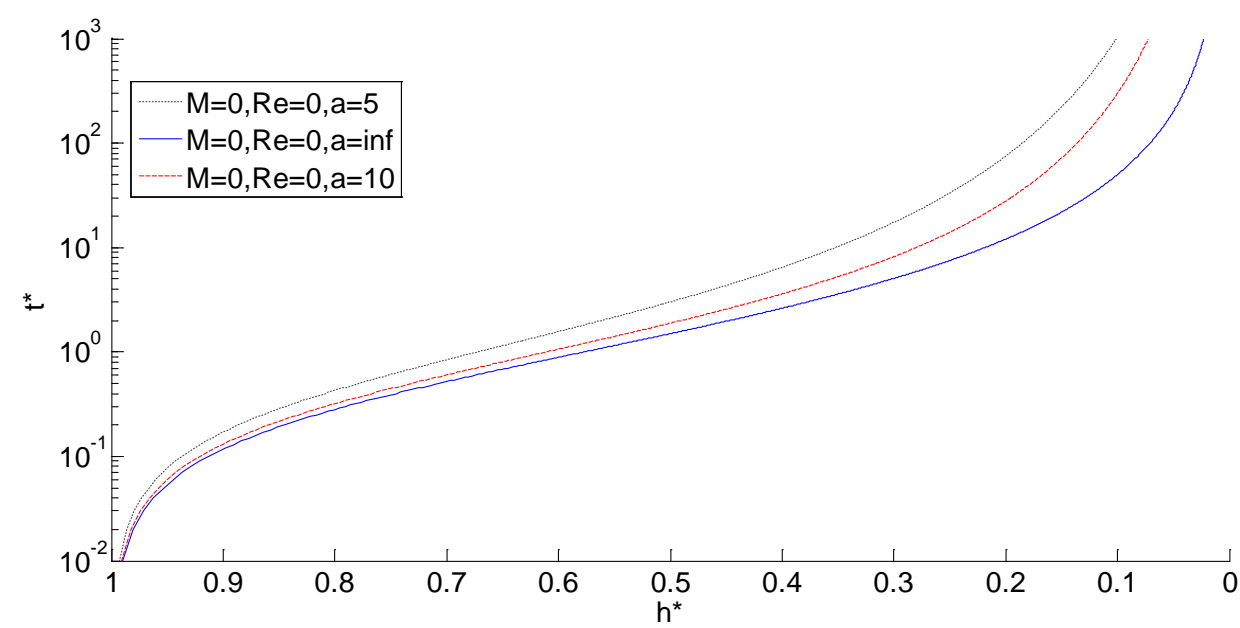

Fig.9. Variation of film thickness $\mathrm{h}^{*}$ with response time $\mathrm{t}^{*}$ for different $\mathrm{h}^{*}$, case1: $\left(\frac{2 M}{a}\langle 1)\right.$

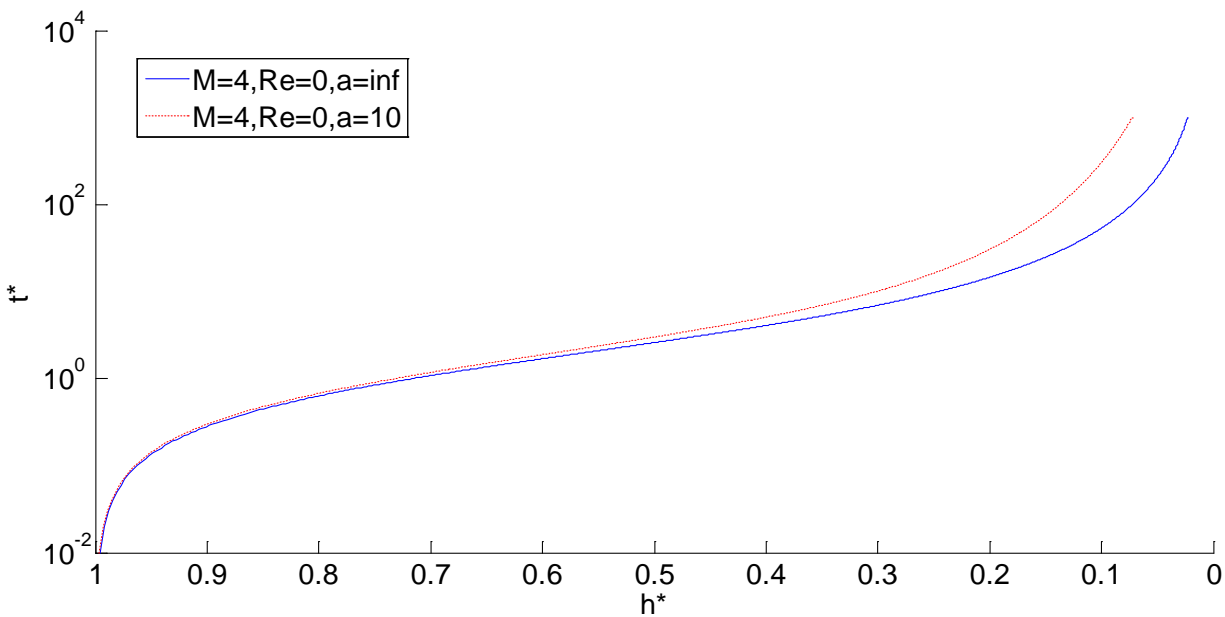

Fig.10. Variation of film height $h^{*}$ with response time $t^{*}$ for different $h^{*}$. case1, $\left(\frac{2 M}{a}\langle 1)\right.$ 
When case 2 is investigated, it is necessary to select values of $M$ and $a$ which satisfy the equality: $\left(\frac{2 M}{a}=1\right)$. Figure 11 shows the generated dimensionless pressure distribution $p^{*}$ for the 3 different sets of inverse couple stress parameter, $a$, Hartman number, $M$ and the convective inertial parameter, Re. For all the 3 sets, the film thickness parameter $h^{*}$ is considered to be constant at $h^{*}=0.5$. Increasing $R e$, results in an increased $p^{*}$, and clearly the load carrying capacity For a non-Newtonian and electrically conducting fluid the variation of load carrying capacity with Reynolds number is shown in figure 12. It is found that an increasing convective inertia leads to enhanced load carrying capacity. This is altogether an accepted outcome due to enhanced flow dynamics. Another outcome of this enhanced flow is improved fluid film response time (figure 13).

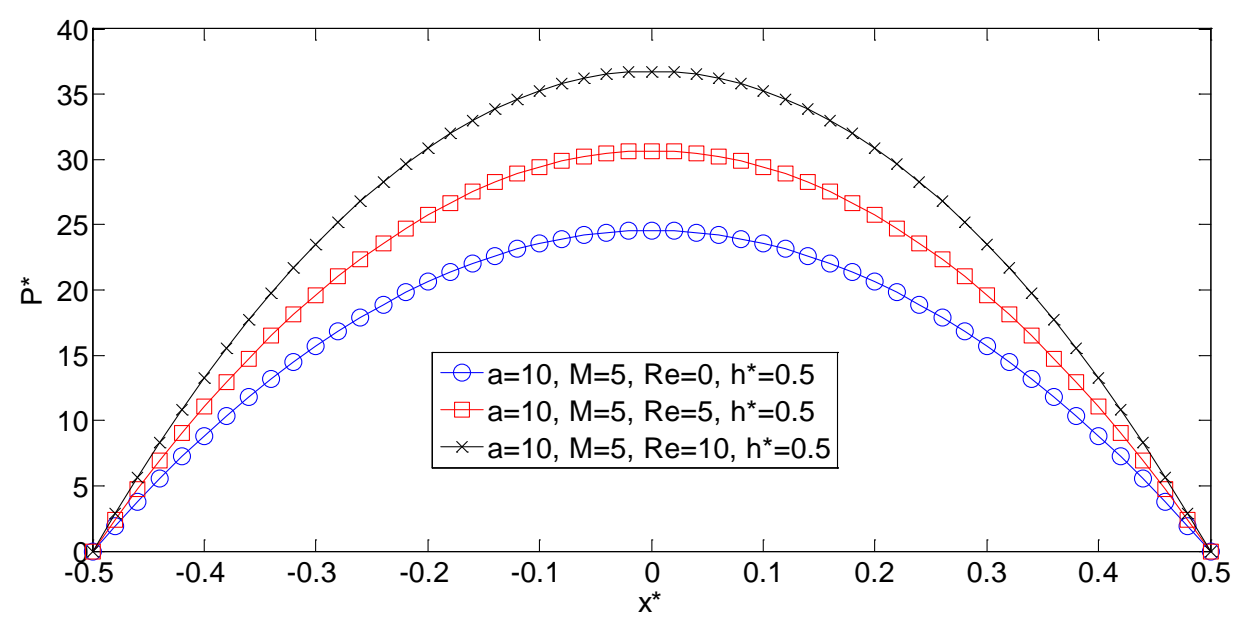

Fig.11: Dimensionless pressure distribution $p^{*}$ for case2: $\left(\frac{2 M}{a}=1\right)$

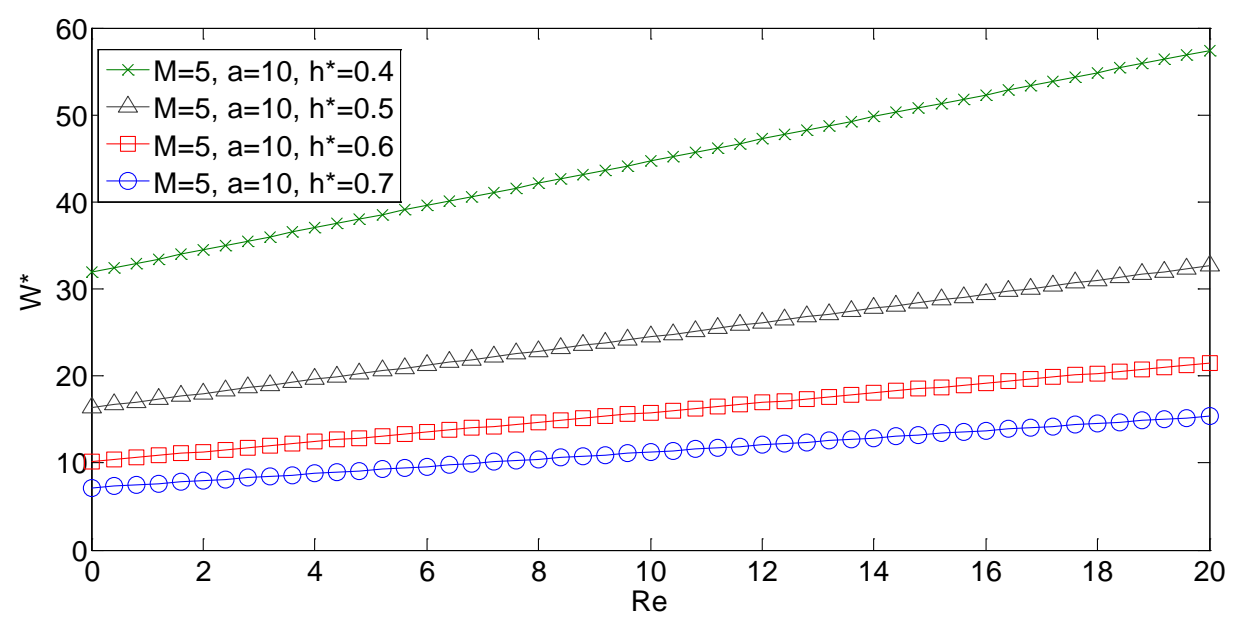

Fig.12: Variation of load capacity $\mathrm{W}^{*}$ with Reynolds number for case2: $\left(\frac{2 M}{a}=1\right)$ 


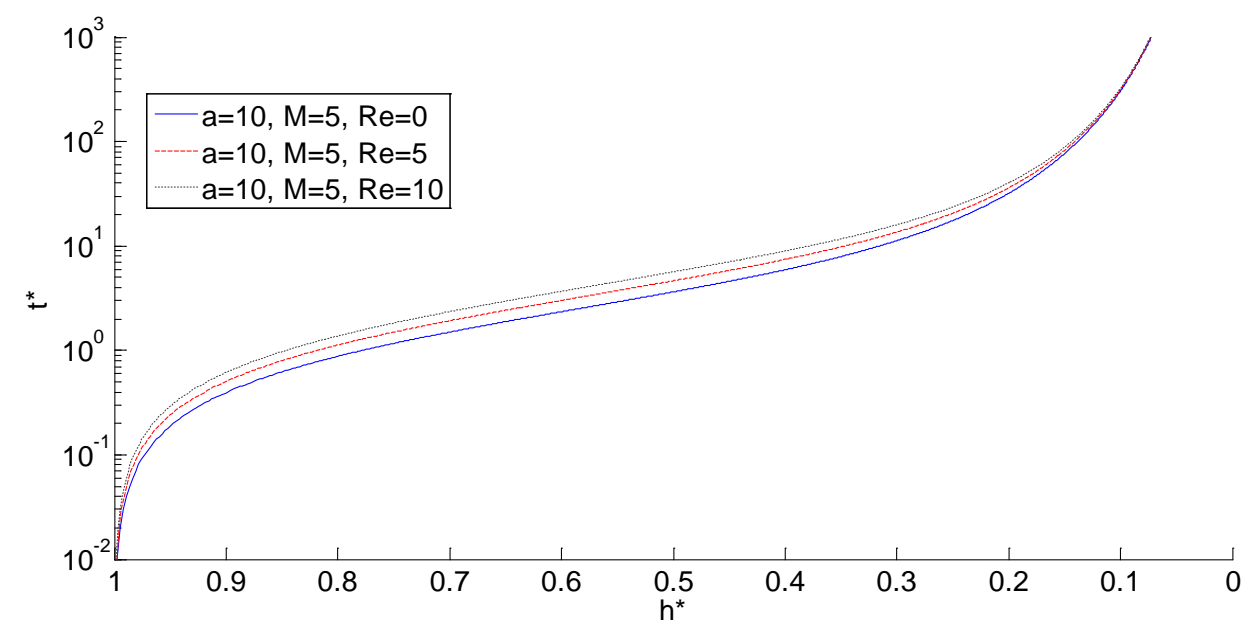

Fig.13: Variation of film thickness $h^{*}$ with response time $t^{*}$ for different $h^{*}$,

$$
\text { for case } 2:\left(\frac{2 M}{a}=1\right)
$$

Case 3: $\left(\frac{2 M}{a}>1\right)$

For investigating case 3, the selected values for $M$ and $a$ should satisfy the above inequality. Dimensionless pressure distribution $p^{*}$ is shown in Figure 14 for different values of convective inertial parameter $R e$ for a constant film thickness of $h^{*}=0.5$. It is found that by increasing $R e$, the generated pressures are enhanced, thus the load carrying capacity.

Figure.15 shows the variation of load capacity $W^{*}$ with couple stress parameter $l^{*}$ for different values of $h^{*}$ under the non-inertial, electrically conducting cases; $R e=0$ and $M=11$. Choosing $M=11$ is because of satisfying mathematical condition of case 3: i.e. $\left.\left(\frac{2 M}{a}\right\rangle 1\right)$. As shown in figure 15, increasing the couple stress parameter $l^{*}$ enhances the load carrying capacity. Figure.16 displays variation of load capacity $W^{*}$ with couple stress parameter $l^{*}$ for different values of $h^{*}$ under the convective inertia and electrically conducting cases $R e=5, M=11$. As shown in the figure, increasing the convective inertial parameter enhances the load carrying capacity. Figure 17 presents variation of load carrying capacity with Hartman number for different values of $R e$. As it can be seen, using an electrically conducting fluid in the presence of magnetic field enhances the load carrying capacity.

Figure 18 shows the variation of film thickness $h^{*}$ with response time $t^{*}$ for different values of $h^{*}$ for various values of $R e$. Increasing values of $R e$ enhance the response time. 


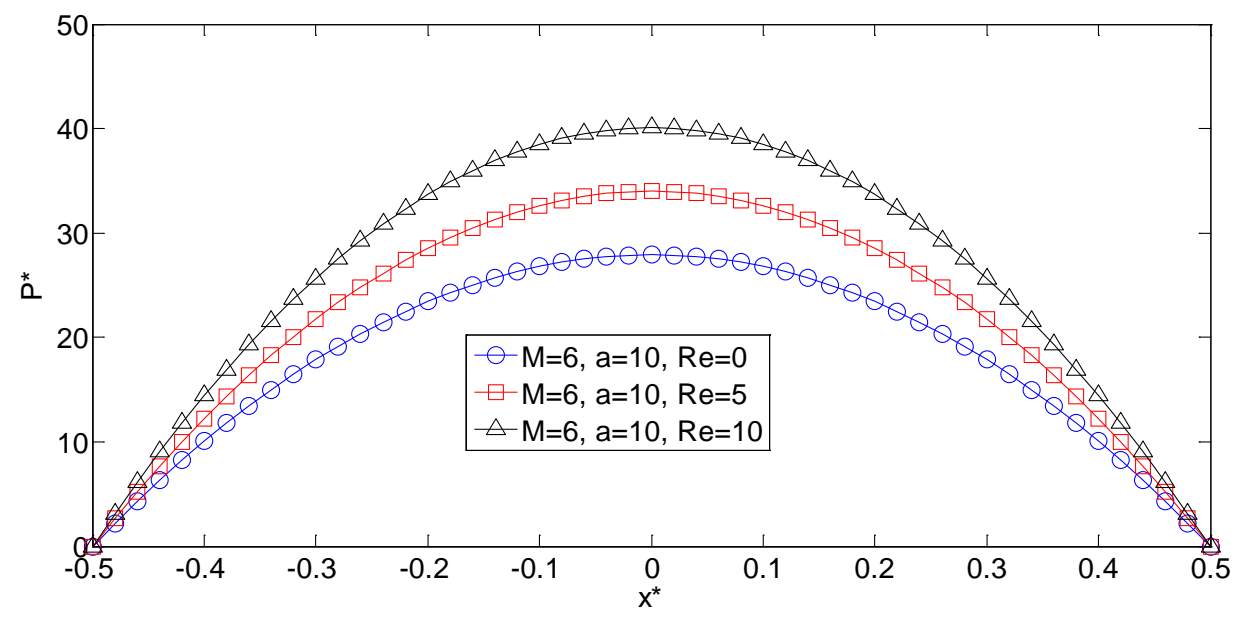

Fig.14. Variation of film pressure $\mathrm{p}^{*}$ with coordinate $\mathrm{x}^{*}$ for $h^{*}=0.5$

$$
\text { .case3: } \left.\left(\frac{2 M}{a}\right\rangle 1\right)
$$

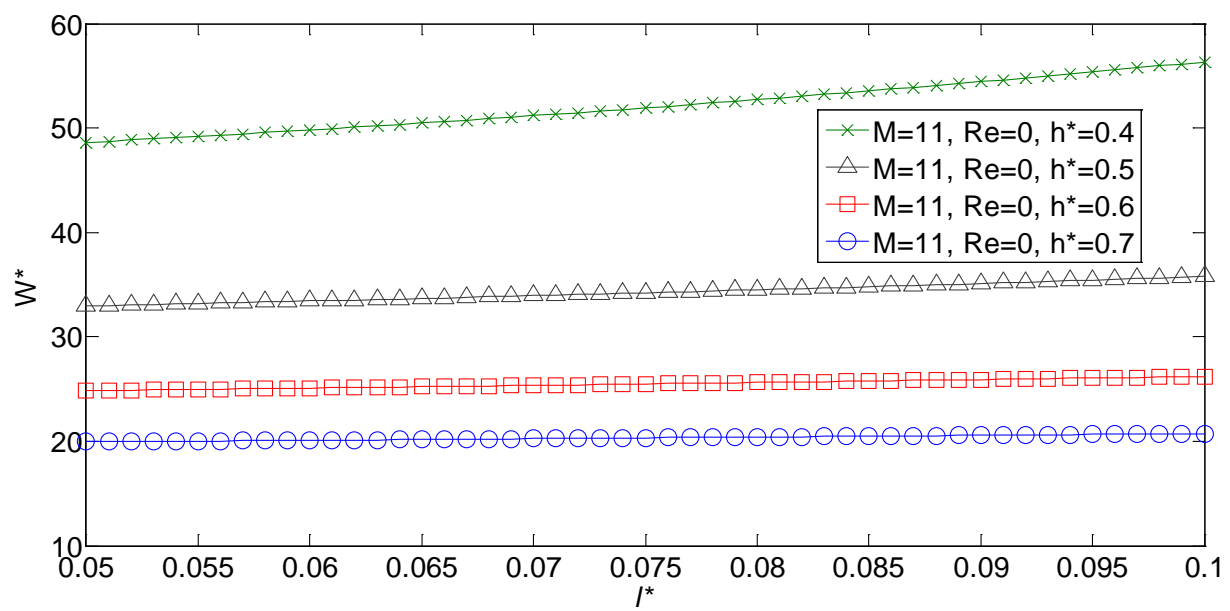

Fig.15. Variation of load capacity $\mathrm{W}^{*}$ with couple stress parameter $l^{*}$ For different $\mathrm{h}^{*}$ case3: $\left.\left(\frac{2 M}{a}\right\rangle 1\right)$

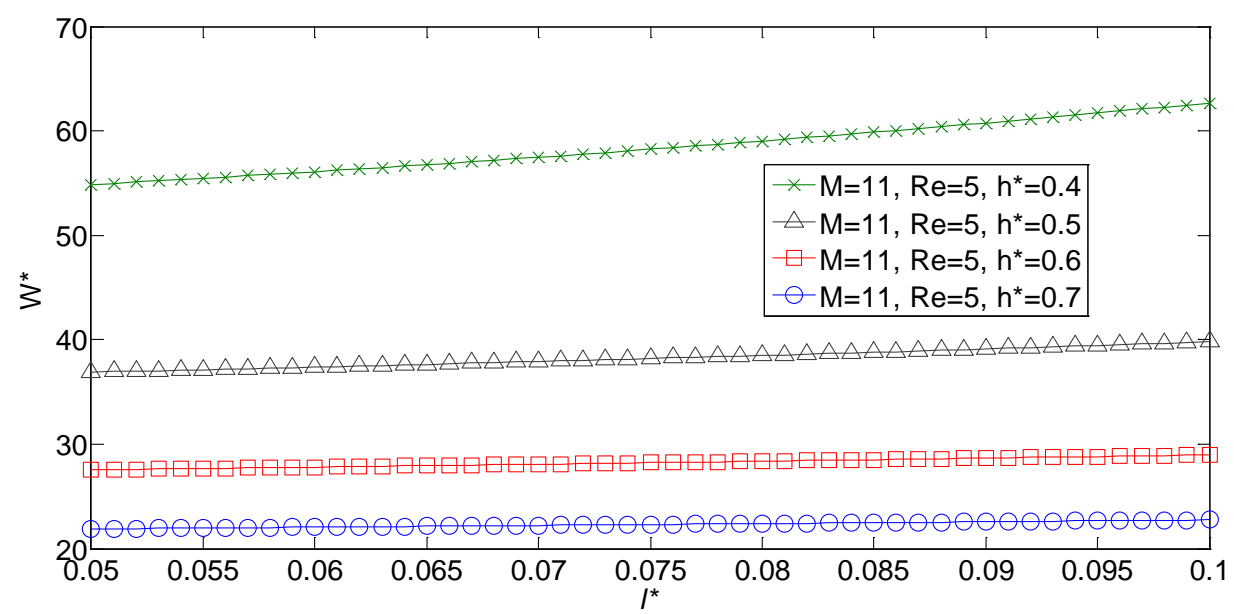


Fig.16. Variation of load capacity $\mathrm{W}^{*}$ with couple stress parameter $l^{*}$ For different $\mathrm{h} *$ case3: $\left.\left(\frac{2 M}{a}\right\rangle 1\right)$

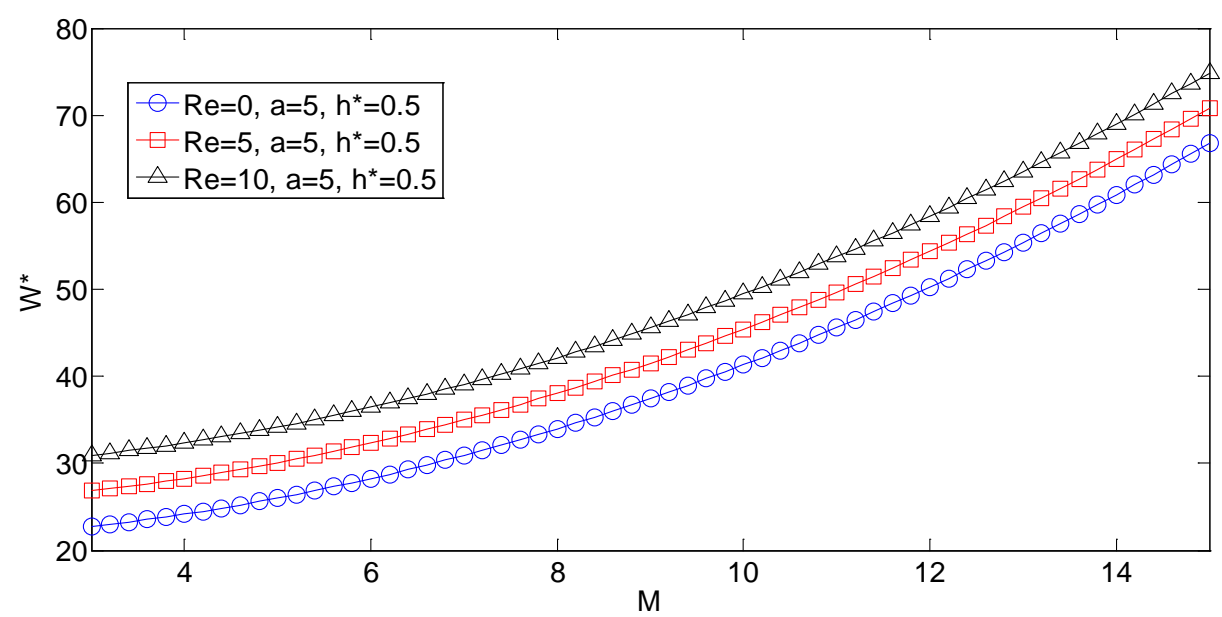

Fig17. Variation of load carrying capacity with Hartman number. under the various values of Re. case3: $\left.\left(\frac{2 M}{a}\right\rangle 1\right)$

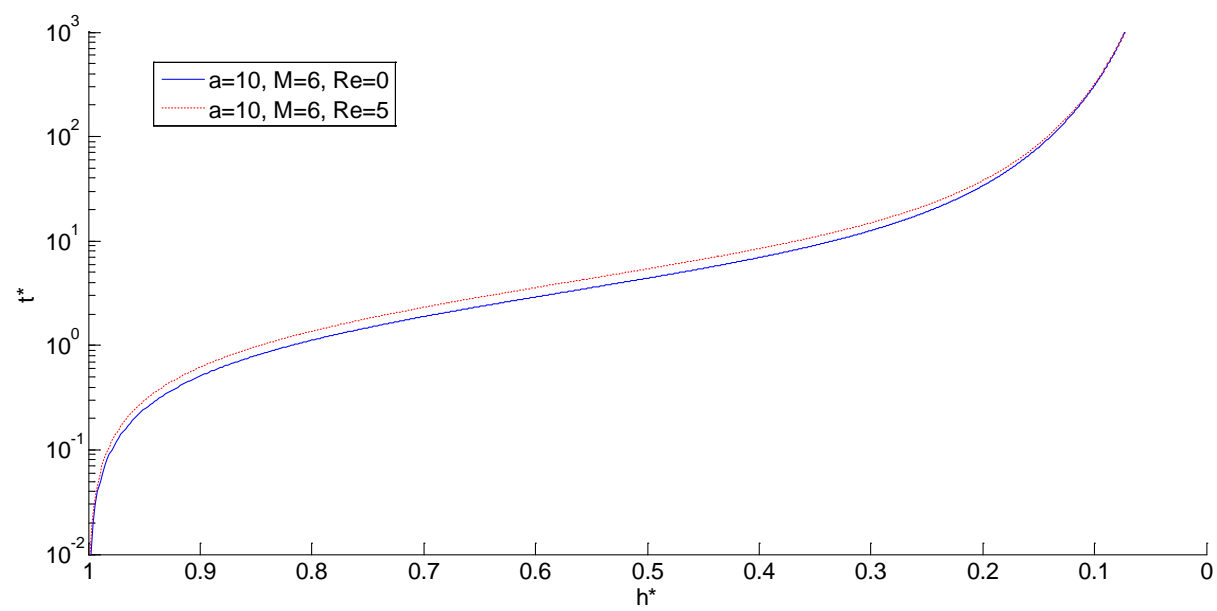

Fig.18. Variation of film height $h *$ with response time $t^{*}$ for different $h *$ under the various values of Re,

$$
\text { case } \left.3:\left(\frac{2 M}{a}\right\rangle 1\right)
$$

\section{Conclusion}

Stokes micro-continuum theory and principle of averaged fluid inertial flow are used to derive a combination of analytical and differential equations for determination of contact conditions for elector-rheological and magneto-rheological fluids in contact of wide plates under squeeze film motion. Variation of pressure distribution, film thickness, load carrying capacity and lubricant film response characteristics subjected to externally applied loads are determined according to the combination of Hartman number, fluid convective inertia, and couple stress parameter. It is shown that in general non-Newtonian MHD couple stress fluids enhance the load carrying capacity 
of the contact and inhibit the incidence of thin films which can result in direct contact of surfaces. Convective inertia also significantly improves the load carrying capacity. However, with impulsive loading the response time of couple stress fluids deteriorates relative to Newtonian lubricants on account of their increased viscosity. An important conclusion of the study is that MHD couple stress fluids are most suited to applications with high steady load intensity. Therefore, for transient conditions some degree of control of supplied magnetic field would be ideal. Furthermore, because of enhanced viscosity such lubricants are best suited to relatively high kinematic contact conditions where usual lubricants are unsuited because of shear thinning. The drawback would be increased viscous friction with MHD couple stress fluids and increased convective inertia.

\section{Acknowledgement}

The authors would like to acknowledge the financial supports from Sahand University of Technology under grant of Research Fund for the Doctoral Program for Higher Education.

\section{References}

[1] Furst EM ,Gast AP. Micromechanics of magnetorheological suspensions. Phys Rev E. 2000;61: 6732-39.

[2] Liao WH , Wang DH. Semi active vibration control of train suspension systems via magnetorheological dampers. J Intelligent Mat. Sys. \& Structures. 2003;4(3: 161172.

[3] Wereley NM, Cho JU, Choi YT and Choi SB. Magnetorheological dampers in shear mode. Smart Mat. \& Structures. 2008;17(1):015022

[4] khouane, F , Dyke SJ.Modeling and identification of a shear mode magnetorheological damper. Mart Mat. \& Structures. 2007;16: 605

[5] Maki ER, Kuzma DC. Magneto hydrodynamic lubrication flow between parallel plates. J Fluid Mech. 1966;26:534-43.

[6] Usha R, Vimala P. Magneto hydrodynamic squeeze film characteristics between parallel circular plates containing a single central air bubble in the inertial flow regime. Journal of Applied Mechanics. 1999;66:1021-3.

[7] Lin JR , Lu RF, Liao WH. Analysis of magneto-hydrodynamic squeeze film characteristics between curved annular plates. Industrial Lubrication and Tribology. 2004;56:300-5.

[8] Lin RF. Magneto-hydrodynamic squeeze film characteristics between annular discs. Ind. LubricTribol. 2001;53:66-71.

[9] Agrawal VK. Inertia Effects in Hydro magnetic Inclined Slider Bearing. Jap J Appl Physics. 1970; 9: 820-24.

[10] Anwar MI , Rodkiewicz CM. Non uniform magnetic field effects in MHD slider bearings. ASME J Lubric Technol. 1972; 94: 101-5.

[11] Gupta JL, Bhat MV. An inclined porous slider bearing with a transverse magnetic field. Wear. 1979;55:359-67.

[12] Ariman T, Sylvester ND. Microcontinuum fluid mechanics, a review. Int J Eng

Sci 1973;11:905-30.

[13] Ariman T, Sylvester ND. Applications of micro continuum fluid mechanics. Int J Eng Sci 1974;12:273-93.

[14] Stokes VK. Couple stresses in fluids. Phys Fluids1966;9:1709-15. 
[15] Ramanaish G, Sarkar P. Squeeze films and thrust bearings lubricated by fluids with couple stress. Wear.1978;48:309-16.

[16] Ramanaish G. Squeeze films between finite plates lubricated by fluids with couple stress. Wear. 1979; 54:315-20

[17] Lin JR. Squeeze film characteristics of long partial journal bearings lubricated with couple stress fluids. Tribo Int. 1997;30:53-8.

[18] Lin JR. Couple-stress effects on the squeeze film characteristics of hemispherical bearings with reference to synovial joints. Appl Mech and Eng. 1996;1:317-32.

[19] Lin JR, Hung CR, and Lu RF. Averaged Inertia Principle For Non- Newtonian Squeeze Films In Wide Parallel Plates: Couple Stress Fluid. Journal of Marine Science and Technology. 2006; 14: 218-24.

[20] Das NC. A study of optimal load-bearing capacity for slider bearing lubricated with couple stress fluids in magnetic field. Tribol Int. 1998; 31:393-400.

[21] Naduvinamani NB , Rajashekar M. MHD couple stress squeeze film characteristics between sphere and plane. Tribology - Materials, Surfaces \& Interfaces. 2011; 5.94-9.

[22] Hamrock BJ. Fundamentals of fluid film lubrication. New York:McGraw-Hill; 1994

\section{Appendix A:}

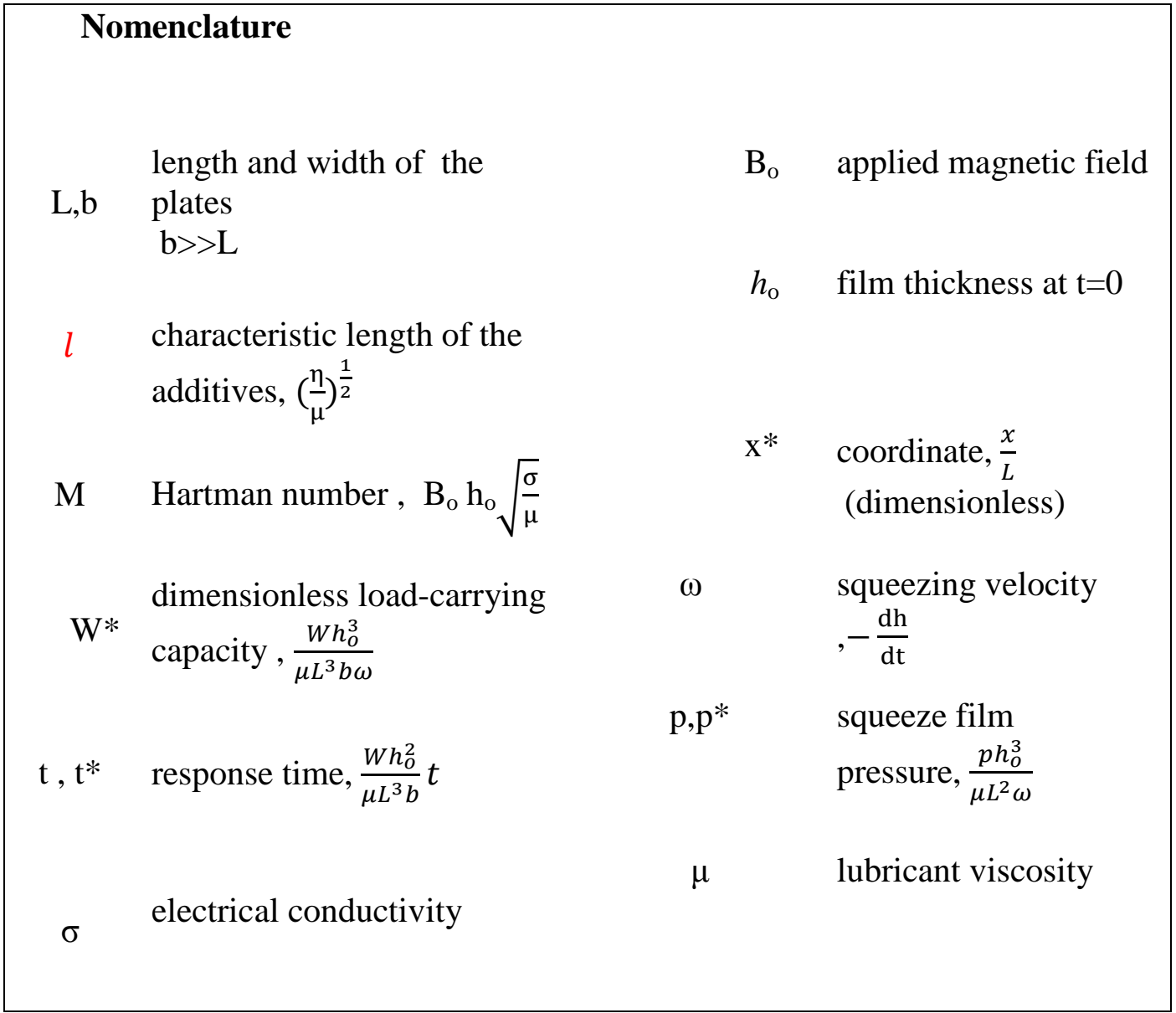




\begin{tabular}{|c|c|c|c|}
\hline $\operatorname{Re}$ & convective inertia & & $\begin{array}{l}\text { material constant } \\
\text { responsible for couple } \\
\text { stress fluids }\end{array}$ \\
\hline $\mathrm{u}^{*}$ & $\begin{array}{l}\text { dimensionless velocity in the } \\
\mathrm{x} \text { direction }, \frac{\mu u}{h_{o}^{2}\left(-g_{m p}\right)}\end{array}$ & & lubricant density \\
\hline$a$ & $\begin{array}{l}\text { inverse coupled stress } \\
\text { parameter, } h_{0} / l\end{array}$ & & $\begin{array}{l}\text { couple stress } \\
\text { parameter, } l / h_{0}\end{array}$ \\
\hline $\mathrm{g}_{\mathrm{mp}}$ & modified pressure gradient & $\mathrm{h}, \mathrm{h}^{*}$ & $\begin{array}{l}\text { Film thickness, } \frac{h}{h_{o}} \\
\text { (dimensionless) }\end{array}$ \\
\hline $\mathrm{u}, \mathrm{w}$ & $\begin{array}{l}\text { velocity components in the } \\
\mathrm{x} \text { and } \mathrm{z} \text { directions } \\
\text { respectively }\end{array}$ & & \\
\hline
\end{tabular}

\section{Appendix B:}

To obtain the contact load carrying capacity, it is necessary to determine the squeeze film pressure distribution, $p^{*}$. This, in turn requires the evaluation of velocity distribution in the contact conjunction. Therefore:

$$
\begin{aligned}
& \text { 1- Case 1: } n=\frac{2 M}{a}\langle 1 \\
& u^{*}=\frac{-1}{M^{2}}\left\{-1+\frac{1}{\alpha^{2}-\beta^{2}}\left[\beta^{2}\left(\frac{\sinh \left(\alpha\left(z^{*}-h^{*}\right)\right)-\sinh \alpha z^{*}}{\sinh \alpha h^{*}}\right)-\alpha^{2}\left(\frac{\sinh \left(\beta\left(z^{*}-h^{*}\right)\right)-\sinh \beta z^{*}}{\sinh \beta h^{*}}\right)\right]\right\}(B 1) \\
& \text { where } \alpha=\frac{a}{\sqrt{2}}\left(1+\sqrt{1-\frac{4 M^{2}}{a^{2}}}\right)^{\frac{1}{2}} \quad \beta=\frac{a}{\sqrt{2}}\left(1-\sqrt{1-\frac{4 M^{2}}{a^{2}}}\right)^{\frac{1}{2}}
\end{aligned}
$$

2- Case 2: $\frac{2 M}{a}=1$ 


$$
u^{*}=\frac{-1}{M^{2}}\left(\begin{array}{l}
-1+\left[\frac{\left(-\cosh \left(\frac{a h^{*}}{\sqrt{2}}\right)+1\right)}{\sinh \left(\frac{a h^{*}}{\sqrt{2}}\right)}+\frac{\frac{\sqrt{2} a h^{*}}{4}\left(-\cosh \left(\frac{a h^{*}}{\sqrt{2}}\right)+1\right) \cosh \left(\frac{a h^{*}}{\sqrt{2}}\right)}{\sin ^{2} h\left(\frac{a h^{*}}{\sqrt{2}}\right)}+\frac{\sqrt{2} a h^{*}}{4}\right] \sinh \left(\frac{a z^{*}}{\sqrt{2}}\right) \\
+\cosh \left(\frac{a z^{*}}{\sqrt{2}}\right)-\frac{\sqrt{2} a z^{*}}{4} \sinh \left(\frac{a z^{*}}{\sqrt{2}}\right)+\frac{\sqrt{2} a z^{*}}{4} \frac{\left(\cosh \left(\frac{a h^{*}}{\sqrt{2}}\right)-1\right)}{\sinh \left(\frac{a h^{*}}{\sqrt{2}}\right)} \cosh \left(\frac{a z^{*}}{\sqrt{2}}\right)
\end{array}\right)
$$

3-Case 3: $\frac{2 M}{a}>1$

$u^{*}=\frac{-1}{M^{2}}\left\{-1+\frac{1}{\alpha_{1}^{2}-\beta_{1}^{2}}\left[\beta_{1}^{2}\left(\frac{\sinh \left(\alpha_{1}\left(z^{*}-h^{*}\right)\right)-\sinh \alpha_{1} z^{*}}{\sinh \alpha_{1} h^{*}}\right)-\alpha_{1}^{2}\left(\frac{\sinh \left(\beta_{1}\left(z^{*}-h^{*}\right)\right)-\sinh \beta_{1} z^{*}}{\sinh \beta_{1} h^{*}}\right)\right]\right\}$

where $\alpha_{1}=\frac{a}{\sqrt{2}}\left(1+i\left(\sqrt{\frac{4 M^{2}}{a^{2}}-1}\right)\right)^{\frac{1}{2}}, \beta_{1}=\frac{a}{\sqrt{2}}\left(1-i\left(\sqrt{\frac{4 M^{2}}{a^{2}}-1}\right)\right)^{\frac{1}{2}}$

Now, let $u=\frac{-h_{o}^{2} g_{m p}}{\mu} u^{*}$ and substitute into the continuity of flow equation (3) and integrate with respect to $z$ over the film thickness. Then, substituting for $u^{*}$ from the above equations and considering a symmetrical pressure condition between the two plates yields:

1- case 1: $n=\frac{2 M}{a}\langle 1$

$g_{m p}=\frac{\mu M^{2} \omega x}{h_{o}^{2} A}$

where:

$A=\left\{-h+\frac{1}{\alpha^{2}-\beta^{2}}\left(\frac{\beta^{2}}{\sinh \frac{\alpha h}{h_{o}}}\left(\frac{2 h_{o}}{\alpha}-\frac{2 h_{o}}{\alpha} \cosh \left(\frac{\alpha h}{h_{o}}\right)\right)-\frac{\alpha^{2}}{\sinh \frac{\beta h}{h_{o}}}\left(\frac{2 h_{o}}{\beta}-\frac{2 h_{o}}{\beta} \cosh \left(\frac{\beta h}{h_{o}}\right)\right)\right)\right\}$

2-Case 2: $n=\frac{2 M}{a}=1$

$g_{m p}=\frac{\mu M^{2} \omega x}{h_{o}^{2} B}$

where: 


$$
B=\left(-h-\frac{\frac{a h}{2}-\frac{3 \sqrt{2} h_{o} \sinh \left(\frac{a h}{\sqrt{2} h_{o}}\right)}{a h_{o} \cos ^{2} h\left(\frac{\sqrt{2} a h}{4 h_{o}}\right)}}{-1}\right.
$$

3-Case 3: $n=\frac{2 M}{a}>1$

$$
g_{m p}=\frac{\mu M^{2} \omega x}{h_{o}^{2} C}
$$

where:

$$
C=\left\{-h+\frac{1}{\alpha_{1}^{2}-\beta_{1}^{2}}\left(\frac{\beta_{1}^{2}}{\sinh \frac{\alpha_{1} h}{h_{o}}}\left(\frac{2 h_{o}}{\alpha_{1}}-\frac{2 h_{o}}{\alpha_{1}} \cosh \left(\frac{\alpha_{1} h}{h_{o}}\right)\right)-\frac{\alpha_{1}^{2}}{\sinh \frac{\beta_{1} h}{h_{o}}}\left(\frac{2 h_{o}}{\beta_{1}}-\frac{2 h_{o}}{\beta_{1}} \cosh \left(\frac{\beta_{1} h}{h_{o}}\right)\right)\right)\right\}
$$

By substituting the modified pressure gradient $g_{m p}$ from equations (B4),(B6),(B8) and the velocity component $u$ from equations (B1),(B2),(B3) into equation (8), one can derive the squeeze film pressure, the load-carrying capacity and the time history of the lubricant film thickness. It should be noted that the thinness of the lubricant film constitutes: $\frac{\partial p}{\partial z}=0$, which means that the viscosity of the lubricant $\mu$ is considered as constant. Therefore, an analytical solution is possible for the three cases considered as:

(a)- Case 1: $n=\frac{2 M}{a}\langle 1$

$$
\frac{\partial p}{\partial x}=\frac{\mu \omega x}{f_{0}\left(h, h_{o}, M, a\right)}-\frac{2 \omega^{2} \rho \times f_{1}\left(h, h_{o}, M, a\right)}{h f_{0}^{2}\left(h, h_{o}, M, a\right)}
$$

The functions $f_{0}\left(h, h_{o}, M, a\right)$ and $f_{1}\left(h, h_{o}, M, a\right)$ are defined as:

$$
f_{0}\left(h, h_{o}, M, a\right)=\frac{h_{o}^{2} A}{M^{2}}
$$




$$
\begin{gathered}
f_{1}\left(h, h_{o}, M, a\right)=\left\{\beta^{4} h_{o}{ }^{4} \frac{\left[\alpha^{3} h-\alpha \beta^{2} h-7 \alpha^{2} h_{o} \sinh \left(\frac{\alpha h}{h_{o}}\right)+3 \beta^{2} h_{o} \sinh \left(\frac{\alpha h}{h_{o}}\right)\right]}{\left[M^{4} \alpha\left(\alpha^{2}-\beta^{2}\right)^{3}\left(\cosh \left(\frac{\alpha h}{h_{o}}\right)+1\right)\right]+}\right. \\
\left\{\begin{array}{l}
\left.\left.h_{o}{ }^{4}\right)\right] \\
{\left[M^{4} \alpha \beta\left(\alpha^{2}-\beta^{2}\right)^{3}\left(\cosh \left(\frac{\beta h}{h_{o}}\right)+1\right)\right]}
\end{array}\right\}+ \\
\left\{\begin{array}{l}
\left.h_{o}{ }^{4} \beta^{5} h-4 \alpha^{5} \beta^{3} h-\alpha \beta^{7} h+2 \alpha^{7} \beta h-3 \alpha^{7} h_{o} \sinh \left(\frac{\beta h}{h_{o}}\right)-\alpha \beta^{7} h \cosh \left(\frac{\beta h}{h_{o}}\right)\right] \\
{\left[M^{4} \alpha \beta\left(\alpha^{2}-\beta^{2}\right)^{3}\left(\cosh \left(\frac{\beta h}{h_{o}}\right)+1\right)\right]}
\end{array}\right\}
\end{gathered}
$$

Applying the boundary conditions (6) and then integrating equation (B10) yields:

$$
p=\left(\frac{\mu \omega}{f_{0}\left(h, h_{o}, M, l\right)}-\frac{2 \omega^{2} \rho f_{1}\left(h, h_{o}, M, l\right)}{h f_{0}^{2}\left(h, h_{o}, M, l\right)}\right)\left(\frac{x^{2}}{2}-\frac{L^{2}}{8}\right)
$$

and using the non-dimensional parameters:

$$
\begin{aligned}
& x^{*}=\frac{x}{L}, p^{*}=\frac{p h_{o}^{3}}{\mu L^{2} \omega}, h^{*}=\frac{h}{h_{o}}, f_{0} *\left(h^{*}, M, a\right)=\frac{f_{0}\left(h, h_{o}, M, a\right)}{h_{o}{ }^{3}}, \operatorname{Re}=\frac{\rho \omega h_{o}}{\mu}, \\
& f_{1}^{*}\left(h^{*}, M, a\right)=\frac{f_{1}\left(h, h_{o}, M, a\right)}{h_{o}{ }^{5}}
\end{aligned}
$$

yields :

$$
p^{*}=\frac{1}{2}\left(\frac{1}{f_{0}^{*}\left(h^{*}, M, a\right)}-\frac{2 \operatorname{Re} f_{1}^{*}\left(h^{*}, M, a\right)}{h^{*} f_{0}^{2} *\left(h^{*}, M, a\right)}\right)\left(x^{* 2}-\frac{1}{4}\right)
$$

Similarly, for cases 2 and 3 the dimensionless pressures are obtained as:

(b)- Case 2: $n=\frac{2 M}{a}=1$

$$
p^{*}=\frac{1}{2}\left(\frac{1}{g_{0} *\left(h^{*}, M, a\right)}-\frac{2 \operatorname{Re} g_{1}^{*}\left(h^{*}, M, a\right)}{h^{*} g_{0}{ }^{2} *\left(h^{*}, M, a\right)}\right)\left(x^{* 2}-\frac{1}{4}\right)
$$

where: 
$g_{0} *\left(h^{*}, M, a\right)=\frac{B}{M^{2} h_{O}}$

$g_{1}^{*}\left(h^{*}, M, a\right)=\frac{h^{*}}{M^{4}}+$

$\frac{\left(\cosh ^{2}\left(\frac{\sqrt{2} a h^{*}}{4}\right)\left(\frac{19 a h^{*}}{16}-\frac{35 \sqrt{2} \sinh \left(\frac{\sqrt{2} a h^{*}}{2}\right)}{16}+\frac{a^{3} h^{* 3}}{96}\right)-\frac{a^{3} h^{* 3}}{64}+\frac{\sqrt{2} a^{2} h^{*^{2}} \sinh \left(\frac{\sqrt{2} a h^{*}}{2}\right)}{16}\right)}{M^{4} a \cosh ^{4}\left(\frac{\sqrt{2} a h^{*}}{4}\right)}($

and:

(c)- Case 3: $\left.n=\frac{2 M}{a}\right\rangle 1$

$p^{*}=\frac{1}{2}\left(\frac{1}{r_{0} *\left(h^{*}, M, a\right)}-\frac{2 \operatorname{Re} r_{1}^{*}\left(h^{*}, M, a\right)}{h^{*} r_{0}{ }^{2}\left(h^{*}, M, a\right)}\right)\left(x^{* 2}-\frac{1}{4}\right)$

where:

$r_{0}^{*}\left(h^{*}, M, a\right)=\frac{C}{M^{2} h_{o}}$

$r_{1} *\left(h^{*}, M, a\right)=\left\{\beta_{1}{ }^{4} \frac{\left[\alpha_{1}{ }^{3} h^{*}-\alpha \beta_{1}{ }^{2} h^{*}-7 \alpha_{1}{ }^{2} \sinh \left(\alpha_{1} h^{*}\right)+3 \beta_{1}{ }^{2} \sinh \left(\alpha_{1} h^{*}\right)\right]}{\left[M^{4} \alpha_{1}\left(\alpha_{1}{ }^{2}-\beta_{1}{ }^{2}\right)^{3}\left(\cosh \left(\alpha h^{*}\right)+1\right)\right]}\right\}+$

$\left\{\frac{\left[3 \alpha_{1}{ }^{3} \beta_{1}^{5} h^{*}-4 \alpha_{1}{ }^{5} \beta_{1}{ }^{3} h^{*}-\alpha_{1} \beta_{1}{ }^{7} h^{*}+2 \alpha_{1}{ }^{7} \beta_{1} h^{*}-3 \alpha_{1}{ }^{7} \sinh \left(\beta_{1} h^{*}\right)-\alpha_{1} \beta_{1}{ }^{7} h^{*} \cosh \left(\beta_{1} h^{*}\right)\right]}{\left[M^{4} \alpha_{1} \beta_{1}\left(\alpha_{1}{ }^{2}-\beta_{1}{ }^{2}\right)^{3}\left(\cosh \left(\beta_{1} h^{*}\right)+1\right)\right]}\right\}+$

$\left\{\frac{\left[\alpha_{1}^{7} \beta_{1} h^{*} \cosh \left(\beta_{1} h^{*}\right)+3 \alpha_{1}{ }^{3} \beta_{1}^{5} h^{*} \cosh \left(\beta_{1} h^{*}\right)-3 \alpha_{1}{ }^{5} \beta_{1}{ }^{3} h^{*} \cosh \left(\beta_{1} h^{*}\right)+7 \alpha_{1}{ }^{5} \beta_{1}{ }^{2} \sinh \left(\beta_{1} h^{*}\right)\right]}{\left[M^{4} \alpha_{1} \beta_{1}\left(\alpha_{1}{ }^{2}-\beta_{1}{ }^{2}\right)^{3}\left(\cosh \left(\beta_{1} h^{*}\right)+1\right)\right]}\right\}$

Appendix C

Table 1: Lubricant rheology

\begin{tabular}{lccl}
\hline Parameter name & symbol & Value & Unit \\
\hline Initial film thickness & $h_{o}$ & $1.667 \times 10^{-5}$ & (metre) $m$ \\
\hline Lubricant viscosity & $\mu$ & $2.449 \times 10^{-4}$ & (Pascal-second) Pa.s \\
\hline $\begin{array}{l}\text { Couple stress material } \\
\text { constants }\end{array}$ & $\eta$ & $0.2722 \times 10^{-14}$ & (Newton-second) N.s \\
\hline
\end{tabular}




\begin{tabular}{lccc}
\hline Lubricant density & $\rho$ & 820 & $\mathrm{~kg} / \mathrm{m}^{3}$ \\
\hline Squeezing velocity & $\omega$ & $8.96 \times 10^{-2}$ & $\mathrm{~m} / \mathrm{s}$ \\
\hline $\begin{array}{l}\text { characteristic length } \\
\text { of the additives }\end{array}$ & $l$ & $3.334 \times 10^{-6}$ & $\mathrm{~m}$ \\
\hline $\begin{array}{l}\text { couple stress } \\
\text { parameter }\end{array}$ & $l^{*}$ & 0.2 & - \\
\hline $\begin{array}{l}\text { inverse couple stress } \\
\text { parameter }\end{array}$ & $a$ & 5 & - \\
\hline \begin{tabular}{l} 
convective inertia \\
\hline
\end{tabular}
\end{tabular}

Table 2: Parameters of the magnetic field

\begin{tabular}{lccl}
\hline Parameter name & Symbol & Value & Unit \\
\hline Initial film thickness & $h_{o}$ & $1.667 \times 10^{-5}$ & (metre) $\mathrm{m}$ \\
\hline Lubricant viscosity & $\mu$ & $2.27 \times 10^{-4}$ & (Pascal-second) Pa.s \\
\hline $\begin{array}{l}\text { Electrical } \\
\text { conductivity }\end{array}$ & $\sigma$ & $3.3 \times 10^{6}$ & ( Siemens per meter ) $\mathrm{S} / \mathrm{m}$ \\
\hline Magnetic field & $B_{o}$ & 2 & (Weber per square metre) $\mathrm{wb} / \mathrm{m}^{2}$ \\
\hline Hartman number & $M$ & 4 & - \\
\hline
\end{tabular}

